\title{
A spatio-temporal geodatabase of mortalities due to respiratory tract diseases in Tehran, Iran between 2008 and 2018: a data note
}

\author{
Elahe Pishgar ${ }^{1}$, Alireza Mohammadi ${ }^{2}$, Nasser Bagheri $^{3}$ and Behzad Kiani $i^{*}$ (I)
}

\begin{abstract}
Objectives: Respiratory tract diseases (RTDs) are among the top five leading causes of death worldwide. Mortality rates due to respiratory tract diseases (MRRTDs) follow a spatial pattern and this may suggest a potential link between environmental risk factors and MRRTDs. Spatial analysis of RTDs mortality data in an urban setting can provide new knowledge on spatial variation of potential risk factors for RTDs. This will enable health professionals and urban planners to design tailored interventions. We aim to release the datasets of MRRTDs in the city of Tehran, Iran, between 2008 and 2018.

Data description: The Research data include four datasets; (a) mortality dataset which includes records of deaths and their attributes (age, gender, date of death and district name where death occurred), (b) population data for 22 districts (age groups with 5 years interval and gender by each district). Furthermore, two spatial datasets about the city are introduced; (c) the digital boundaries of districts and (d) urban suburbs of Tehran.
\end{abstract}

Keywords: Respiratory tract diseases, Mortality, Space-time analysis, Clustering, Geographical information systems, Tehran, Iran

\section{Objective}

Respiratory tract diseases (RTDs) have a major impact on disease burden including death across the world [1]. RTDs are among the top five leading causes of death worldwide and Covid-19 has brought RTDs in focus [2, 3]. More than 9.5 million deaths globally are attributed to RTDs with four million premature death per year $[3,4]$. Previous Research demonstrated possible links between mortality rates due to respiratory tract diseases (MRRTDs) and environmental risk factors [5].

\footnotetext{
*Correspondence: kiani.behzad@gmail.com

${ }^{4}$ Department of Medical Informatics, School of Medicine, Mashhad

University of Medical Sciences, Mashhad, Iran

Full list of author information is available at the end of the article
}

Urbanization, air pollution and sedentary lifestyle are associated with an increased risk of asthma and respiratory diseases in urban areas compared to the rural regions [6]. Tehran is the capital city of Iran and is the 22nd most populous city in the world with a population of 10 million people at daytime. It has the highest MRRTDs in Iran [7]. The high population size, the natural diversity of the surrounding areas (windswept deserts, plains, and mountains) and the existence of industries have extensively increased the level of air pollution in this mega-city [8]. It is necessary to conduct a spatiotemporal analysis of the current epidemiological patterns of MRRTDs in Tehran to identify the potential links between MRRTDs and environmental risk factors. Spatio-temporal analyses of mortality data can provide new knowledge on spatial variation of MRRTDs and potential 
drivers of this variation. To support research in this field we aim to release the datasets of MRRTDs in Tehran, between 2008 and 2018 .

\section{Data description}

Geographical information system (GIS) has a great capacity to integrate diverse data from different sources including spatial, temporal and descriptive components into one framework. $[9,10]$. Spatial component represents information about the physical location of health event and the shape of geometric objects. Temporal data refer to the time of occurrence and descriptive information relates to attribute data about the event (i.e. age, gender and cause of death) [11,12]. GIS provides appropriate tools for collecting, geo-linking, analysing and visualising geographical patterns and spatio-temporal relationships in the distribution of RTDs or deaths with potential environmental factors $[13,14]$.

Data on 43,176 death events due to RTDs from September 2008 to September 2018 were obtained from the Behesht-e Zahra Organization, a local health department under the supervision of the Tehran Municipality [15]. This dataset includes date of death, age, gender, cause of death and urban district where death was occurred (dataset 1). Population data were obtained from the Statistical Centre of Iran and they contain the annual population size by district in Tehran from 2008 to 2018. We categorised the gender as male and female. Age of people was categorised into five groups including $0-14,15-24$, $25-44,45-64$ and $>65$ years old (dataset 2 ). The digital boundaries of districts data (data file 3) and districts' map sheets were obtained from the municipality of Tehran (data file 4) [16, 17]. Table 1 shows the details of each dataset and provides access links to these data.

The datasets provided in this study can be used by researchers in different disciplines such as health geography, urban planning, medicine and healthcare ecosystem research. Descriptive choropleth maps can be produced to highlight the MRRTDs distribution in Tehran during 2008-2018. Choropleth map is a common map used to represent data on predetermined geographic areas [18]. Researchers may use Empirical Bayesian procedures for smoothing mortality rates in the case of a choropleth map. Empirical Bayesian also help to identify local clusters of more/less affected areas [19]. High-mortality clusters (hot spots) show the regions having a significantly greater mortality rate and Low-mortality clusters reveal the regions with a significantly lower mortality rate (cold spots) in Tehran. Global Moran's Index can be used to show the degree of spatial autocorrelation in the pattern of MRRTDs. In other words, it can test whether the mortalities distribute randomly or follow a spatial pattern [20].

In addition to spatio-temporal analyses, these data can be linked to the contextual factors such as climate status, air pollution and smoke to further investigated the impact of environmental risk factors on MRRTDs. The research outputs can inform health policymakers and urban planners to develop appropriate strategies to reduce the risk of MRRTDs across communities.

This study offers Tehran's MRRTDs data for the period 2008-2018. Further, Covid-19 disease has become a pandemic disease in late 2019 and our data provide a new opportunity for researchers to quantify and assess the impact of Covid-19 disease on MRRTDs burden in Tehran.

\section{Limitations}

Tehran is a mega city with an area of $730 \mathrm{~km}^{2}$ and comprises 22 districts. In this study, we aggregated the data at district level which is relatively a coarse geography and may mask variation at finer geography level such as mesh blocks.

\section{Abbreviations \\ RTDs: Respiratory tract diseases; MRRTDs: Mortality rates due to respiratory tract diseases; GIS: Geographical information system.}

\section{Acknowledgements}

We would like to express our deepest gratitude to Behesht-e Zahra Organization of Tehran, affiliated to the Tehran Municipality for providing and offering the data.

Table 1 Overview of data sets

\begin{tabular}{|c|c|c|c|}
\hline Label & Name of data file/data set & File types (file extension) & $\begin{array}{l}\text { Data repository and identifier (DOI } \\
\text { or accession number) }\end{array}$ \\
\hline Dataset 1 & Mortality data & MS Excel file $\left(^{*} . x \mid s x\right)$ & $\begin{array}{l}\text { Harvard Dataverse } \\
\text { https://doi.org/10.7910/DVN/NFKDWC }\end{array}$ \\
\hline Dataset 2 & Population data & MS Excel file (*.xlsx) & $\begin{array}{l}\text { Harvard Dataverse } \\
\text { https://doi.org/10.7910/DVN/NFKDWC }\end{array}$ \\
\hline Data file 3 & Tehran_border & Shape file (*.shp) & $\begin{array}{l}\text { Harvard Dataverse } \\
\text { https://doi.org/10.7910/DVN/NFKDWC }\end{array}$ \\
\hline Data file 4 & Tehran_districts & Shape file (*.shp) & $\begin{array}{l}\text { Harvard Dataverse } \\
\text { https://doi.org/10.7910/DVN/NFKDWC }\end{array}$ \\
\hline
\end{tabular}




\section{Authors' contributions}

EP prepared the data. AM and BK drafted and revised the manuscript. NB critically reviewed the manuscript. BK is the principal investigator and research leader. All authors read and approved the final manuscript.

\section{Funding}

This research did not receive any grants from funding agencies in the public, commercial, or non-profit sectors.

\section{Availability of data and materials}

The data described in this Data note can be freely and openly accessed on Harvard Dataverse under https://doi.org/10.7910/DVN/NFKDWC [21]. Please see Table 1 and reference list for details and link to the data.

\section{Ethics approval and consent to participate}

The informed consent was not required to be obtained due to the nature of the study.

\section{Consent for publication}

Not applicable.

\section{Competing interests}

The authors declare that they have no competing interests.

\section{Author details}

${ }^{1}$ Department of Human Geography and Logistics, Faculty of Earth Science, Shahid Beheshti University, Tehran, Iran. ${ }^{2}$ Department of Geography \& Planning, Faculty of Social Sciences, University of Mohaghegh Ardabili, Ardabil, Iran. ${ }^{3}$ Visualization and Decision Analytics (VIDEA) Lab, Centre for Mental Health Research, Research School of Population Health, College of Health and Medicine, The Australian National University, Canberra, Australia. ${ }^{4}$ Department of Medical Informatics, School of Medicine, Mashhad University of Medical Sciences, Mashhad, Iran.

Received: 3 August 2020 Accepted: 30 September 2020 Published online: 07 October 2020

\section{References}

1. Burney $P$, Jarvis D, Perez-Padilla R. The global burden of chronic respiratory disease in adults. Int J Tuberc Lung Dis. 2015;19(1):10-20. https://doi. org/10.5588/ijtld.14.0446.

2. Bergquist R, Rinaldi L. Covid-19: Pandemonium in our time. Geospatial Health. 2020;15(1). https://doi.org/10.5588/ijtld.14.0446.

3. Paul E, Brown GW, Ridde V. COVID-19: time for paradigm shift in the nexus between local, national and global health. BMJ Glob Health. 2020:5(4):e002622. https://doi.org/10.1136/bmjgh-2020-002622.

4. Wong AH, Tran T. CD151 in respiratory diseases. Front Cell Dev Biol. 2020;8:64. https://doi.org/10.3389/fcell.2020.00064.

5. Mokoena KK, Ethan CJ, Yu Y, Shale K, Liu F. Ambient air pollution and respiratory mortality in Xi'an, China: a time-series analysis. Respir Res. 2019;20(1):139. https://doi.org/10.1186/s12931-019-1117-8.

6. Sciaraffa R, Borghini A, Montuschi P, Gerosa G, Ricciardi W, Moscato U. Impact of air pollution on respiratory diseases in urban areas: a systematic review Daniele Ignazio La Milia. Eur J Public Health. 2017. https://doi. org/10.1093/eurpub/ckx189.117.

7. National Organization For Civil Registration (NOCR). Yearbook of Demographic Statistics 2019. Tehran, Iran: Bureau of Demographic and
Immigration Statistics; 2020 2019. Contract No.: 304/6. https://www.sabte ahval.ir/avej/default.aspx?tabid $=1499$

8. Namvar Z, Yunesian M, Shamsipour M, Hassanvand MS, Naddafi K, Shahhosseini E. Cross-sectional associations between ambient air pollution and respiratory signs and symptoms among young children in Tehran. Atmos Environ. 2020;223:117268. https://doi.org/10.1016/j.atmos env.2020.117268

9. Kiani B, Raouf Rahmati A, Bergquist R, Moghaddas E. Comparing spatiotemporal distribution of the most common human parasitic infections in Iran over two periods 2007 to 2012 and 2013 to 2018: a systematic quantitative literature review. Int J Health Plan Manag. 2020. https://doi. org/10.1002/hpm.3010

10. Hoseini B, Bagheri N, Kiani B, Azizi A, Tabesh H, Tara M. Access to dialysis services: a systematic mapping review based on geographical information systems. Geospatial Health. 2018;13(1):3-10. https://doi.org/10.4081/ gh.2018.577.

11. Shabanikiya H, Hashtarkhani S, Bergquist R, Bagheri N, Vafaeinejad R, Amiri-Gholanlou M, et al. Multiple-scale spatial analysis of paediatric, pedestrian road traffic injuries in a major city in North-Eastern Iran 2015-2019. BMC Public Health. 2020;20:1-11. https://doi.org/10.1186/ s12889-020-08911-2.

12. Hashtarkhani S, Kiani B, Bergquist R, Bagheri N, VafaeiNejad R, Tara M. An age-integrated approach to improve measurement of potential spatial accessibility to emergency medical services for urban areas. Int J Health Plan Manag. 2020;35(3):788-98. https://doi.org/10.1002/hpm.2960.

13. Goshayeshi L, Pourahmadi A, Ghayour-Mobarhan M, Hashtarkhani S, Karimian S, Dastjerdi RS, et al. Colorectal cancer risk factors in northeastern Iran: a retrospective cross-sectional study based on geographical information systems, spatial autocorrelation and regression analysis. Geospatial Health. 2019;14(2):219-28. https://doi.org/10.4081/gh.2019.793.

14. Halimi L, Bagheri N, Hoseini B, Hashtarkhani S, Goshayeshi L, Kiani B. Spatial analysis of colorectal cancer incidence in Hamadan Province, Iran: a retrospective cross-sectional study. Appl Spatial Anal Policy. 2020;13(2):293-303. https://doi.org/10.1007/s12061-019-09303-9.

15. Tehran Municipality (TM). Tehran Statistical yearbooks 2006-2017. PDF formatfile. Tehran: Tehran Municipality, organization I; 2019. Report No.: 1. https://statistics.tehran.ir/Default.aspx

16. Tehran's Air Quality Control Company (TAQCC). Tehran's Online Noise Pollution Data Archive. Tehran: Tehran Municipality; 2019. Contract No.: 2019/01/02.https://air.tehran.ir/

17. Tehran Municipality (TM). Atlas of Tehran Metropolis. Tehran; 2018.https:// atlas.tehran.ir/

18. Besançon L, Cooper M, Ynnerman A, Vernier F. An evaluation of visualization methods for population statistics based on choropleth maps. arXiv preprint arXiv:2005.00324. 2020.

19. Lawson AB. Bayesian disease mapping: hierarchical modeling in spatial epidemiology. Boca Raton: CRC Press; 2013. ISBN-13: 978-1584888406.

20. Taddese AA, Baraki AG, Gelaye KA. Spatial modeling, prediction and seasonal variation of malaria in northwest Ethiopia. BMC Res Notes. 2019;12(1):1-6. https://doi.org/10.1186/s13104-019-4305-1.

21. Kiani B. Data for: mortality due to respiratory tract diseases in Tehran Iran between 2008 and 2018. 2020. https://doi.org/10.7910/DVN/NFKDWC.

\section{Publisher's Note}

Springer Nature remains neutral with regard to jurisdictional claims in published maps and institutional affiliations. 